\title{
Abuse Experienced by Elderly Residing in a Community of Pokhara, Nepal
}

Pramila Bhandari ${ }^{1}$, Mira Adhikari ${ }^{2 *}$

Author Info:

1Department of Nursing, Pokhara Technical Health Multipurpose Institute, Pokhara, Nepal

${ }^{2}$ Department of Adult Nursing, Pokhara Nursing Campus, Pokhara, IOM, TU

\section{Corresponding Author:}

Mira Adhikari, Pokhara Nursing Campus, Pokhara, Institute of Medicine, Tribhuvan university Email/Contact: memirabaral@gmail.com

\section{ABSTRACT}

Background: Abuse of the elderly is a hidden problem in Nepalese community. Pokhara city is highly affected by urbanization, modernization and migration that predispose older adults to social isolation and financial difficulties increasing their risk to abuse. This study aims to fill the gap in the knowledge in the area of abuse of elderly in Pokhara city.

Objectives: The major objective of this study was to determine the prevalence of caregiver abuse experienced by the older adults and find out the factors associated with the abuse.

Method: This was a cross sectional study. Convenience sampling technique was used and data was collected from 192 elderly above the age of 60 years residing a community of Pokhara-28, Kaski at their households using a structured interview schedule. Data was collected in June 2018, for a period of one month. Before data collection, informed written consent was taken from participants. The data was analyzed by using SPSS-16 and chi-square test was used as inferential statistics to determine the association between the elder abuse and selected variables.

Result: We found out that $65.6 \%$ of the elderly experienced at least one form of abuse in the last 6 months. The most common forms of abuse were caregiver neglect (55.2\%) and psychological abuse (38.5\%). The elderly abuse was statistically significant with female sex $(p=0.001)$, unmarried/widow/widower/ separated/divorced $(p=.021)$, illiterate $(p=0.002)$, and among those having chronic illness $(p=0.003)$.

Conclusion: Almost 7 out of 10 elderly experienced abuse in the past 6 months. The most common form of abuse was caregiver neglect followed by psychological and financial abuse. Older adults who were females, unmarried/widowed/separated/ divorced, illiterate and those having chronic disease were at higher risk for abuse.

Keywords: Elder abuse, prevalence, risk

\begin{tabular}{|c|c|}
\hline QR Code & Article Info \\
\hline \multirow[b]{2}{*}{ (ه) View PDF } & Published Online: 30 December 2020 \\
\hline & How to cite this article in Vancouver Style? \\
\hline & $\begin{array}{l}\text { Bhandari } \mathrm{P} \text {, Adhikari M,. Abuse Experienced by Elderly Residing in a Community of Pokhara, Nepal. } \\
\text { Europasian J Med Sci.2020;2(2):77-83. https://doi.org/10.46405/ejms.v2i1.221 }\end{array}$ \\
\hline & Disclaimer: \\
\hline \multirow{3}{*}{$\begin{array}{l}\text { Scan Me for } \\
\text { Full Text }\end{array}$} & Conflict of Interest: None Declared; \\
\hline & $\begin{array}{l}\text { Copyright: ( } \odot 2020 \text { by author(s). This is an open access article distributed under the terms of the Creative } \\
\text { Commons Attribution International License } 4.0 @ \text { @ } @ \text { which permits unrestricted use, distribution, and } \\
\text { reproduction in any medium, provided the original work is properly cited. }\end{array}$ \\
\hline & Publisher's Note: \\
\hline \multicolumn{2}{|c|}{$\begin{array}{l}\text { The Europasian Journal of Medical Sciences (EJMS) (www.europasianjournals.org) is an official Journal of Nirvana Psychosocial Care Center } \\
\text { \& Ressearch Institute (www.nirvanapscc.com). The Journal as well as publisher remain neutral with regards to any jurisdictional claims in } \\
\text { any published articles, its contents and the institutional affiliations of the authors. }\end{array}$} \\
\hline
\end{tabular}




\section{INTRODUCTION}

Worldwide, older adults are the fastest growing segment of the population. ${ }^{1}$ Many developed countries have adopted the chronological age of 65 years to define older adults, ${ }^{2}$ however, in Nepal $60+$ years is referred to as older citizens. ${ }^{3}$

Abuse of the older adults is a social problem throughout the globe. World Health Organisation (WHO) has defined elder abuse as "a single, or repeated act, or lack of appropriate action, occurring within any relationship where there is an expectation of trust which causes harm or distress to an older person". Elder abuse can take various forms that include physical, psychological, sexual and financial. ${ }^{6}$ It can also result from intentional or unintentional neglect. WHO estimates that $15.7 \%$ of people 60 years and older are subjected to abuse. ${ }^{6}$

Various changes in older adults increase their risk of being abused. Older adults experience physical weakness and are dependent on others. ${ }^{5-6}$ Further, longevity of the older adults, erosions of the norms and values that supported the elders and provided them with respect in the families and the community, have made older adults at risk for abuse..$^{7-9}$ The social security system of a country have some role in preventing abuse among the older adults. The Government of Nepal has implemented some provisions to support the older adults but studies suggest that they are not enough to address the needs of the older adults. ${ }^{10-11}$ Studies suggest a high prevalence of abuse of elderly in Nepal. ${ }^{12-13}$

Elder abuse is a growing problem in Nepal and urgently requiring the attention of the government. Older abuse is a hidden and an underestimated and understudied problem in Nepal. Studies on the abuse of elderly in Nepal are very scant. Pokhara is one of the cities from where a huge number of young adults migrate to the foreign land for job each year leaving behind their older parents at their homes. Family disintegration due to migration and increased dependence due to ageing causes social isolation and lack of support to the elderly which increases the risk of their abuse. ${ }^{14-15}$

However, no any similar studies has been conducted in Pokhara to study the status of abuse of older adults. Therefore, the researchers have chosen this topic in order to explore the abuse faced by elders in the city to fill in the gap in the knowledge in the field.

\section{MATERIALS AND METHODS}

This is a cross sectional study carried out in Pokhara city to assess the prevalence of abuse among elders residing in the city. The population for the study was older adults aged over 60 years (completed $60^{\text {th }}$ birthday) residing in the community of Kalika, Pokhara-28.

Convenience sampling technique was used to collect data from 192 study participants. Male or Female elders aged who were above the age of 60 years and were residing in the community and willing to participate in the study were included in the study. Elders who could not communicate either due to language problem or due to hearing problem or having severe mental illness and those not willing to participate in the study were excluded from the study.

Structured interview schedule was used for data collection. The tool was developed by the researchers themselves being based on the literature review and other validated tools $16,17,18,19$

Validity of the instrument was established by developing instrument on the basis of literature review and consultation with experts in the related area. Pretesting of the instrument was done in 10\% population in ward no. 12 of total estimated size to assess clarity, adequacy, and consistency of the tool. After pretesting, some modification was made in the tool to make questions simpler and clear. The data was checked for reliability and the chronbach's alpha value for the tool was 0.71 , which is within the acceptable level. ${ }^{20}$

Prior to data collection permission was taken from the research committee of Pokhara Campus. Then formal permission for study was taken from concerned ward for the study. Then, the household were selected conveniently. The elderly living in the household were identified; they were explained about the purpose of the study and their participation in the study. They were explained that they can leave the interview any time if they wish to discontinue. Then, informed written consent for the study was taken, and after obtaining the consent, face to face interview was taken. Interview was taken in a separate room in the house. For those houses where there was no separate room to maintain privacy, data was collected in the field where no one was present. In the household with more than one elders, data was collected from all the elderly in the household separately. Data was collected for a period of one month in June, 2018. 
The duration for interview for each participant was 20-30 minutes. Confidentiality was ensured by using the information for the research purpose only. Privacy was maintained while collecting data from each study participants by taking the data in a separate place, away from the family/group. Data was collected by researcher themselves. Obtained data was used for the study purpose only.

Further to data collection, in co-ordination with the "Mothers' Groups" of the ward, a class was organized to the community people regarding physical and psychological support for elderly and legal provisions set by the Nepal Government regarding protection and support of the elderly.

The collected data was reviewed, organized, edited and coded using SPSS (statistical Package for Social Sciences) version 16, data was analyzed using descriptive statistics (interpreted in terms of frequency, percentage, mean and standard deviation) and Chi- square test was used as an inferential statistics to find out the association of abuse with socio-demographic characteristics.

In this study, physical abuse refers to pushing, slapping, throwing something at, handling roughly, or beating the elderly. Psychological abuse in this study refers to yelling or speaking bitter words at elderly for their poor personal functioning, blaming elderly for anything they did not do, threatening or shouting cursing the elderly, and criticizing, insulting, excluding or ignoring the older adults. Financial abuse in this study refers to forcing elderly to spend their money against their will or restricting elderly to spend money against will and forcing elderly to sign financial papers against will. Neglect in this study refers to not including elderly in decision making related to them, refraining elderly from buying food, clothes, medicines and other commodities as needed. Sexual abuse in this study refers to forcing elderly by others including spouse for natural/unnatural sexual intercourse despite will. Elderly who scored positive response in any of the 10 questions indicating abuse were categorized as being abused.

\section{RESULTS}

This study revealed that more than half of the elderly were within the age of $60-69$ years $(53.1 \%)$ and were females (53.1\%). Majority of elders were married and living with spouse (74.0\%), $63.5 \%$ of them were from nuclear family and $97.9 \%$ had their children. More than half of the participants had attained primary education (52.6\%) and $75 \%$ of the total participants were currently unemployed, and $31.2 \%$ of the elderly had their old age incentive as their major source of income. However, $77.1 \%$ of the participants had their own property, and $84.4 \%$ reported that they got help from their family members in need. (Table 1)

Table 1: Background characteristics of elderly

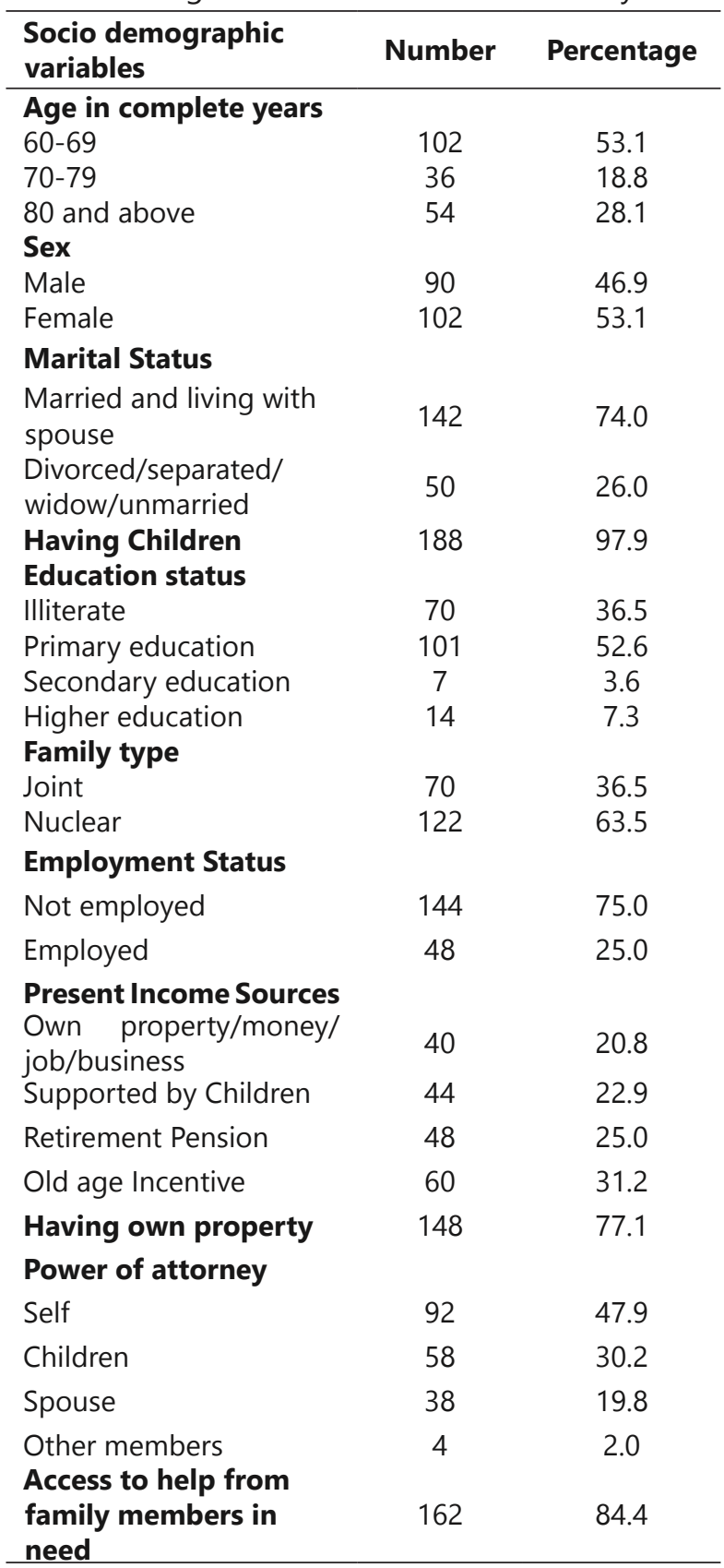

Majority of the elderly living in the community had chronic illness (63.5\%) and $61.5 \%$ were taking medicine for the conditions whereas $9.4 \%$ had disabilities. Among the elders, $4.2 \%$ had hearing problem. Regarding personal habits, $33.3 \%$ of elders reported that they smoke and/or intake 
Table 2: Health related characteristics of the elderly

\begin{tabular}{llc}
\hline Medical condition & Number & Percentage \\
\hline $\begin{array}{l}\text { Having chronic } \\
\text { illness }\end{array}$ & 122 & 63.5 \\
$\begin{array}{l}\text { Taking medicine } \\
\text { for illness }\end{array}$ & 118 & 61.5 \\
$\begin{array}{l}\text { Disabilities } \\
\text { Having hearing }\end{array}$ & 18 & 9.4 \\
problem & 8 & 4.2 \\
Vision problem & 6 & 3.1 \\
Walking problem & 4 & 2.1 \\
$\begin{array}{l}\text { Other problem } \\
\text { Personal Habits }\end{array}$ & 4 & 2.1 \\
$\begin{array}{l}\text { Drinking alcohol } \\
\text { Smoking and/or }\end{array}$ & 4 & \\
tobacco intake & 64 & 2.1 \\
\hline
\end{tabular}

tobacco and $2.1 \%$ reported that they drink alcohol. (Table 2). Out of total respondents, $65.6 \%$ of the elderly reported that they experienced some form of abuse over the past 6 months. Among the total participants, $55.2 \%$ reported that they experienced neglect followed by psychological abuse (38.5\%) while the least reported physical abuse (3.1\%). (Table 3). This study showed a significant association of elderly abuse with female sex $(p=0.001)$, female sex $(p=0.001)$, illiteracy $(p=0.002)$ and unmarried/widowed/separated/ divorced $(p=0.021)$ and illiteracy $(p=0.002)$ but no any significant association could be seen with age, type of family and employment status. (Table 4) Table 3: Prevalence of abuse among elderly

\begin{tabular}{lcc}
\hline Prevalence of abuse & Number & Percentage \\
\hline Experienced abuse & $\mathbf{1 2 6}$ & $\mathbf{6 5 . 6}$ \\
Neglect & 106 & 55.2 \\
Psychological abuse & 74 & 38.5 \\
Financial abuse & 44 & 22.9 \\
Physical abuse & 6 & 3.1 \\
Sexual abuse & 24 & 12.5 \\
\hline
\end{tabular}

This study showed that elder abuse is significantly associated with having chronic illness $(p=0.003)$. However no significant association could be seen between abuse of elderly with alcohol intake, having property, having disabilities and dependency status. (Table 5)
Table 4: Association of socio demographic variables with abuse among elderly

\begin{tabular}{|c|c|c|c|}
\hline & \multicolumn{2}{|c|}{ Experienced abuse } & \multirow[t]{2}{*}{ P-Value } \\
\hline & Yes & No & \\
\hline \multicolumn{4}{|l|}{ Age } \\
\hline $60-69$ & $64(62.7 \%)$ & $38(37.3 \%)$ & 0.458 \\
\hline 70 and above & $62(68.9 \%)$ & $28(31.1 \%)$ & \\
\hline \multicolumn{4}{|l|}{ Sex } \\
\hline Male & $48(53.3 \%)$ & $42(46.7 \%)$ & $0.001^{*}$ \\
\hline Female & $78(76.5 \%)$ & $24(23.5 \%)$ & \\
\hline \multicolumn{4}{|l|}{ Education } \\
\hline Illiterate & $56(80.0 \%)$ & $14(20.0 \%)$ & $0.002^{*}$ \\
\hline Literate & $70(57.4 \%)$ & $52(42.6 \%)$ & \\
\hline \multicolumn{4}{|l|}{ Marital status } \\
\hline $\begin{array}{l}\text { Married } \\
\text { (living with } \\
\text { spouse) }\end{array}$ & $86(60.6 \%)$ & $56(39.4 \%)$ & $0.021^{*}$ \\
\hline $\begin{array}{l}\text { Divorced/ } \\
\text { Separated } \\
\text { /Widow/ } \\
\text { unmarried }\end{array}$ & $40(80.0 \%)$ & $10(20.0 \%)$ & \\
\hline \multicolumn{4}{|c|}{ Having children } \\
\hline Yes & $124(66.0 \%)$ & $64(34.0 \%)$ & 0.894 \\
\hline No & $2(50.0 \%)$ & $2(50.0 \%)$ & \\
\hline \multicolumn{4}{|c|}{ Type of family } \\
\hline Nuclear & $84(68.9 \%)$ & $38(31.1 \%)$ & 0.278 \\
\hline Joint & $42(60.0 \%)$ & $28(40.0 \%)$ & \\
\hline \multicolumn{4}{|c|}{ Employment status } \\
\hline Employed & $32(66.7 \%)$ & $16(33.3 \%)$ & 1 \\
\hline Unemployed & $94(65.3 \%)$ & $50(34.7 \%)$ & \\
\hline
\end{tabular}

\section{DISCUSSION}

Elder abuse is a common social problem in Nepal. This study revealed that $65.6 \%$ of the elderly experienced some forms of abuse in the past 6 months. More than half of the elderly (55.2\%) reported that they experienced caregiver neglect followed by $38.5 \%$ of the elders who reported psychological abuse. The finding is higher compared to other studies. ${ }^{21,22,23,24}$ This may be attributed to the differences in setting. This study was conducted in Pokhara, Kaski where international migration of younger generation for job is very high. Thus most of the elderly in this city are either left alone or with daughter in laws and grandchildren. Further, 
Table 5: Association of personal habits, financial and health conditions of elderly with their abuse

\begin{tabular}{llll}
\hline & \multicolumn{2}{c}{ Experienced abuse } & P-Value \\
\cline { 2 - 3 } & Yes & No & \\
\cline { 1 - 2 } Drinking Alcohol & & \\
Yes & $4(100.0 \%)$ & $0(0 \%)$ & - \\
No & $122(64.9 \%)$ & $66(35.1 \%)$ &
\end{tabular}

\section{Own Property}

$\begin{array}{llll}\text { Yes } & 92(62.2 \%) & 56(37.8 \%) & 0.094 \\ \text { No } & 34(77.3 \%) & 10(22.7 \%) & \end{array}$

\section{Chronic illness}

$\begin{array}{llll}\text { Yes } & 90(73.8 \%) & 32(26.2 \%) & 0.003 * \\ \text { No } & 36(51.4 \%) & 34(48.6 \%) & \\ \text { Disabilities } & & & \\ \text { Yes } & 14(77.8 \%) & 4(22.2 \%) & 0.332 \\ \text { No } & 110(63.2 \%) & 64(36.8 \%) & \end{array}$

\section{Dependency Status for self-care expenses}

\begin{tabular}{llll}
$\begin{array}{l}\text { Dependent } \\
\text { Self- }\end{array}$ & $32(72.7 \%)$ & $12(27.3 \%)$ & 0.343 \\
dependent & $94(63.5 \%)$ & $54(36.5 \%)$ & \\
\hline
\end{tabular}

around one fourth of the participants of the study were divorced, separated or widowed. ${ }^{22,24}$ This may have resulted in the higher rates of abuse of those elderly.

This study shows that $12.5 \%$ of the elderly experienced sexual abuse. The finding is higher to other studies. ${ }^{21,22,23} \mathrm{Nepal}$ is a male dominated society where females' interest are poorly considered. In Nepal, even for married couples, there is dominance of male partners in establishing the sexual relation without regards to the wish of their partner, and such physical relationship is considered normal. The query to this hidden aspect in married elderly addressed in the interview and the comfort in conversation with the female interviewer could have helped to generate the hidden feelings of sexual abuse among the participants.

This study showeds that elder abuse was associated with female sex $(p=0.001)$. The study is consistent with other studies conducted in Western Nepal which showed that the older abuse was associated with female sex. ${ }^{25}$ Similar studies conducted in India and Korea concluded that females were at a more risk for abuse than the males. ${ }^{26,27}$ This may be related to the patriarchal dominance over the females both physically and emotionally. Further, gender differences in social roles of females, usually a passive role of women in Nepalese community may have increased the risk for abuse among female elderly. Similarly, this study revealed that illiteracy of the elderly was associated with their abuse $(p=0.002)$. The finding is similar to a study conducted in India which showed that education is strongly associated with decreased vulnerability to abuse. ${ }^{28}$ This may be because education increases the confidence, employment and a sense of selfrespect and respect by others in the society, decreasing the risk of being abused in the Nepalese society. However, this study revealed no significant association between age of participants and elder abuse $(p=0.458)$. This study also showed no any significant association between elder abuse with type of family and employment status.

This study dipicted that marital status is associated with abuse among the elderly $(p=0.021)$. In respect to the chronic diseases, this study showed significant association of abuse with chronic diseases among the elderly $(p=0.002)$. The finding is supported by a study conducted in Brazil which showed that elder abuse is more common among divorced and separated elders and those with poor health. 29 This may be because being unmarried, widow/ widower, divorced and separated may have caused older adults to live alone and become socially isolated increasing their risk of being abused. Further, chronic disease is often associated with need for increased care of elderly by caregivers, more financial expenses and decreased physical capacity that increases their dependence to others for basic activities of living increasing their risk of being abused. Similarly, this study showed that majority of the participants (31.2\%) had the old age incentive as a major source of income. However, the amount of the incentive is insufficient for the elderly to meet their basic needs. ${ }^{30}$ A study conducted in Nepal showed that $30 \%$ of the elderly do not meet health care facility despite having a disease condition, and low annual income was associated with underutilization of health services. ${ }^{31}$ Hence living with chronic diseases and physical limitation leads to physical suffering, functional disability and increased susceptibility to abuse.

There are some limitations to this study. The study was small scale ward based study conducted in a community of Pokhara city with limited sample size. This study excludes the elderly who were severely ill and on total dependent on caregivers in their houses, those who are at a higher risk for abuse. Further, the findings are based on the reported abuse on perception of the elderly and are not observed and validated with the caregiver. 


\section{CONCLUSION}

Most of elderly living in the community of Pokhara City experienced some forms of abuse and the major form of abuse they experienced was caregiver neglect followed by psychological abuse. Abuse of the elderly was significantly associated with female sex, unmarried/widowed/separated and divorced status, illiteracy and presence of chronic illness. It is recommended that the government conduct education and public awareness campaigns on elder abuse, its prevention and control, and develop several empowerment programs for elderly that can protect the elderly from abuse.

We would like to acknowledge the concerned authority of the ward for providing us the permission to conduct the study. Further, we would like to express our sincere thanks to all the elderly who participated in the study.

\section{REFERENCES}

1. United Nations. Ageing, 2019. Geneva, Switzerland. Accessed on August 13, 2020 [Full Text]

2. Nepal Law Commission. Senior Citizens Act, 2063 (2006), 2018. Accessed on september4, 2020 [Full Text]

3. World Health Organisation. Ageing and Health, 2020. Accessed on September 4, 2020 [Full Text]

4. World Health Organisation. Elder Abuse. June 15, 2020. Accessed on September 9, 2020. Available [Full Text]

5. World Health Organisation. Ageing and life courses. 2020. Accessed on October 5, 2020 [Full Text]

6. Centre for Disease Control and Prevention. Preventing elder abuse. May 12, 2020. Accessed on June 24, 2020 [Full Text]

7. UNDESA. Health inequalities in old age, 2015. Accessed on June 1, 2020 [Full Text]

8. Shrestha DK. Giving up on Grannies. Nepali Times, 04 October 2012. Accessed on June 5, 2020[Full Text]

9. United Nations, Economic and Social Commission for Asia and the Pacific. Country Report, Nepal, 2007. On May 7, 2020 [Full Text]

10. Malakar I, Chalise HN. Perception of Elderly towards Social Security Allowance in Nepal. South Asian Journal of Social Studies and Economics. 2018:1-9. DOI: 10.9734/SAJSSE/2018/46449 [Google Scholar] [Full Text]

11. Acharya S, Ghimire S, Jeffers EM, Shrestha N. Health care utilization and health care expenditure of Nepali older adults. Frontiers in public health. 2019 Feb 15;7:24. https://doi.org/10.3389/fpubh.2019.00024 [Google Scholar] [PubMed] [PMC] [Full Text]
12. Yadav UN, Tamang MK, Paudel G, Kafle B, Mehta S, Chandra Sekaran V, Gruiskens JR. The time has come to eliminate the gaps in the under-recognized burden of elder mistreatment: A community-based, cross-sectional study from rural eastern Nepal. PloS one. 2018 Jun 20;13(6):e0198410. [Google Scholar] [PubMed] [Full Text]

13. Chalise HN, Paudel BR. Elderly Abuse among Community-Living Older Adults of Least Developed Country-Nepal. Arch Phys Rehabil Med. 2020;1(1):18. DOI: APRM-1(1)-002 [Google Scholar][Full Text]

14. Ghimire S, Singh DR, Nath D, Jeffers EM, Kaphle M. Adult children's migration and well-being of left behind Nepalese elderly parents. Journal of Epidemiology and Global Health. 2018 Dec;8(3):154-61.[ Google Scholar] [PubMed] [Full Text]

15. Speck S. "They moved to city areas, abroad": views of the elderly on the implications of outmigration for the Middle Hills of Western Nepal. Mountain Research and Development. 2017 Nov;37(4):425-35. [Google Scholar] [Full Text]

16. Schofield MJ, Mishra GD. Validity of self-report screening scale for elder abuse: Women's Health Australia Study. The Gerontologist. 2003 Feb 1;43(1):110-20. https://doi.org/10.1093/ geront/43.1.110 [Google Scholar] [PubMed] [PMC] [Full Text]

17. Neale AV, Hwalek MA, Scott RO \& Stahl C. Validation of the HwalekSengstock elder abuse screening test. Journal of Applied Gerontology. 1991 10(4), 406415. https://doi.org/10.1177/1049731516654573. [Google Scholar] [Full Text]

18. Yadav UN, Paudel G. Prevalence and associated factors of elder mistreatment: a cross sectional study from urban Nepal. Age and ageing. $2016 \mathrm{Sep}$ 1;45(5):609-13.HS-EAST. https://doi.org/10.1093/ ageing/afw112 [Google Scholar] [PubMed] [PMC] [Full Text]

19. Yaffe MJ, Wolfson C, Lithwick $M$, Weiss $D$. Development and validation of a tool to improve physician identification of elder abuse: The Elder Abuse Suspicion Index (EASI) C. Journal of Elder Abuse \& Neglect. 2008 Jun 12;20(3):276-300. DOI: $10.1080 / 08946560801973168$ [Google Scholar] [PubMed] [PMC] [Full Text]

20. Taber KS. The use of Cronbach's alpha when developing and reporting research instruments in science education. Research in Science Education. 2018 Dec 1;48(6):1273-96. https://doi.org/10.1007/ s11165-016-9602-2 [Google Scholar] [Full Text]

21. Chalise HN, Basnet M. Abuse of older adults residing in the community of Nepal. J Gerontol Geriatr Res. 2017;6(2):1-5. DOI: 10.4172/2167-7182.1000415 [Google Scholar][Full Text]

22. Yadav UN, Paudel G. Prevalence and associated 
factors of elder mistreatment: a cross sectional study from urban Nepal. Age and ageing. 2016 Sep 1;45(5):609-13. https://doi.org/10.1093/ageing/ afw112 [Google Scholar] [PubMed] [PMC] [Full Text]

23. Biggs S, Manthorpe J, Tinker A, Doyle M, Erens B. Mistreatment of older people in the United Kingdom: Findings from the first national prevalence study. Journal of Elder Abuse \& Neglect. 2009 Jan 14;21(1):1-4. DOI: $10.1080 / 08946560802571870$ [Google Scholar] [PubMed] [PMC] [Full Text]

24. Laumann EO, Leitsch SA, Waite LJ. Elder mistreatment in the United States: Prevalence estimates from a nationally representative study. The Journals of Gerontology Series B: Psychological Sciences and Social Sciences. 2008 Jul 1;63(4):S248-54. DOI: 10.1093/geronb/63.4.s248 [Google Scholar] [Full Text]

25. Chalise HN, Paudel BR. Elderly Abuse among Community-Living Older Adults of Least Developed Country-Nepal. Arch Phys Rehabil Med. 2020;1(1):18. DOI: APRM-1(1)-002. [Google Scholar] [Full Text]

26. Sebastian D, Sekher TV. Abuse and neglect of elderly in Indian families: Findings of elder abuse screening test in Kerala. J Indian Acad Geriatr. 2010 Jun;2:5460. Accessed on June 6, 2020 from http://www.jiag. org/pdf/15/1.pdf [Google Scholar] [Full Text]
27. Jeon GS, Cho SI, Choi K, Jang KS. Gender differences in the prevalence and correlates of elder abuse in a community-dwelling older population in Korea. International journal of environmental research and public health. 2019 Jan;16(1):100. DOI: 10.3390/ ijerph16010100 [Google Scholar] [Full Text]

28. Skirbekk V, James KS. Abuse against elderly in IndiaThe role of education. BMC public health. $2014 \mathrm{Dec}$ 1;14(1):336. https://doi.org/10.1186/1471-2458-14336 [Google Scholar] [Full Text]

29. Burnes $D$, Pillemer $K$, Caccamise $P L$, Mason $A$, Henderson Jr CR, Berman J, Cook AM, Shukoff D, Brownell $P$, Powell $M$, Salamone A. Prevalence of and risk factors for elder abuse and neglect in the community: a population-based study. Journal of the American Geriatrics Society. 2015 Sep;63(9):1906-12. DOI: 10.1111/jgs.13601 [Google Scholar] [PubMed] [PMC] [Full Text]

30. Malakar I, Chalise HN. Perception of Elderly towards Social Security Allowance in Nepal. South Asian Journal of Social Studies and Economics. 2018:19. https://doi.org/10.9734/sajsse/2018/v2i430008 [Google Scholar][ Full Text]

31. Acharya S, Ghimire S, Jeffers EM, Shrestha N. Health care utilization and health care expenditure of Nepali older adults. Frontiers in public health. 2019 Feb 15;7:24. https://doi.org/10.3389/fpubh.2019.00024 [Google Scholar] [PubMed] [PMC] [Full Text] 